\title{
The Anatomy of the Plantar Arterial Arch
}

\author{
Anatomía del Arco Plantar Arterial
}

\author{
A. Kalicharan*; P. Pillay*; C. Rennie* \& M. R. Haffajee*
}

KAliChaRAN, A.; PILlay, P.; RENNIE, C. \& HAFFAJEE, M. R. The anatomy of the plantar arterial arch. Int. J. Morphol., 33(1):36-42, 2015.

SUMMARY: The plantar arterial arch provides the dominant vascular supply to the digits of the foot, with variability in length, shape, and dominant blood supply from the contributing arteries. According to the standard definition, the plantar arterial arch is formed from the continuation of the lateral plantar artery and the anastomoses between the deep branch of dorsalis pedis artery. In this study, 40 adult feet were dissected and the plantar arch with variations in shape and arterial supply was observed. The standard description of the plantar arch was observed in $55 \%$ of the specimens with variations present in $45 \%$. Variations in terms of shape were classified into three types: Type A (10\%): plantar arterial arch formed a sharp irregular curve; type B (60\%): obtuse curve; type C (3\%): spiral curve. Variation in the dominant contributing artery was classified into six types: type A (25\%), predominance in the deep branch of dorsalis pedis artery supplying all digits; type B (5\%), predominance in the lateral plantar artery supplying digits 3 and 4; and type C (20\%), predominance in the deep branch of dorsalis pedis artery supplying digits 2 to 4; type D (24\%), equal dominance showed; type E (10\%), predominance in the lateral plantar artery supplying digits 3 to 5; and type $\mathrm{F}(21 \%$ ), predominance of all digits supplied by lateral plantar artery. The foot was divided into three parts to determine the location of the plantar arterial arch. The second part was further divided into three parts: middle anterior $(90 \%)$, intermediate middle $(10 \%)$, and middle posterior $(0 \%)$. Knowledge of the vascular anatomy of the plantar arterial arch is crucial for understanding sites of partial amputations.

KEY WORDS: Arterial supply; Variations; Plantar arch; Foot; Vascular surgery.

\section{INTRODUCTION}

Thorough knowledge of the arterial supply of the foot, specifically the plantar arterial supply, is of great importance in vascular reconstruction (Yamada et al., 1993), particularly in cases of motor vehicle accidents and severe ischema of the lower limb (Friedman et al., 1990; Luther \& Lepäntalo, 1997). In addition, accurate knowledge of the arterial patterns and variations becomes necessary in reconstructive surgery involving donation of various parts of the foot. The archus plantaris (Schuenke et al., 2010), deep plantar arch (Ozer et al., 2005; Gabrielli et al., 2001), or more commonly referred to as the plantar arterial arch since it is formed from two plantar arteries (Feneis \& Dauber, 2000), is the main source of arterial supply to the foot (Standring, 2009). It is generally accepted that the arterial supply of the foot involves a triple supply system i.e., the distributing arteries are the anterior tibial, posterior tibial and peroneal arteries, with the source of blood being derived from the external iliac artery (Standring). The posterior tibial artery is the larger of the terminal branches of the popliteal artery, coursing inferomedially through the lower leg, terminating midway between the medial malleolus and the pterion of the calcaneus by bifurcating into medial and lateral plantar arteries (Standring). The lateral plantar artery passes obliquely across the sole of the foot forming the plantar arterial arch that is completed by a deep branch from the dorsalis pedis artery (Standring; Moore et al., 2010; Kelikian \& Sarrafian, 2011). Bergman et al. (1988) found that the posterior tibial artery may be absent, rudimentary or replaced by the fibular artery. This study also illustrated that the plantar arch may be doubled or absent, in which case the plantar tissues of the foot are supplied by a single artery, the posterior tibial artery. Rarely, in the absence of the posterior tibial artery, the peroneal artery develops into the medial and lateral plantar arteries.

Although several studies have addressed the arterial anatomy of the foot, a more detailed study of the arch and its branches, such as their morphological and morphometric variations, are scarcely documented (Ozer et al.; Gabrielli et al.; Kelikian \& Sarrafian; Sidawy, 2006; Moore et al.).

\footnotetext{
" Clinical Anatomy School of Laboratory Medicine and Medical Sciences College of Health Sciences, University of KwaZulu-Natal, KwaZulu-Natal, South Africa.
} 
According to much older studies by Dubreuil-Chamberdel (1925) and Adachi (1928) on 200 cadaveric feet, the plantar arterial arch supplies the digits of the foot via the plantar metatarsal arteries, including all the muscles and bones, however, these studies noted few morphological variations.

More recent studies conducted by Ozer et al. and Gabrielli et al., have illustrated the contributing arteries and the positioning of the plantar arch within the foot, documenting a few anatomical variations in this region. In 2008, Anupama investigated the plantar arterial arch in 50 formalin fixed cadavers, and confirmed the findings of the above mentioned authors (Moore et al.; Ozer et al.) and had not noted any further differences. Farlex (2014) confirmed the position of the plantar arterial arch within the foot as described by Ozer et al. and Gabrielli et al., but further refined it by stating that it lies on the transverse arch of the foot.

Therefore, the aims of the study were to: a) re-examine and describe the morphology of the plantar arterial arch, b) illustrate the morphometry of the plantar arterial arch, in particular, the length, diameter, form of the arch, and document its variations, c) determine the dominant contributors to the plantar arch, and d) compare the plantar arterial arch with regards to side symmetry and sex.

\section{MATERIAL AND METHOD}

The plantar arterial arch was dissected in 40 lower limbs (20 right and 20 left; 24 male, 16 female) in adult cadaveric specimens. These specimens were obtained and examined, in accordance with Chapter 8 of the National Health Act No. 61 of 2003, within the Department of Clinical Anatomy, University of KwaZulu Natal, Westville campus. Ethical clearance was obtained from the University (Ethical Clearance Approval Number: LMMSEC 026/13). Adult specimens of the foot that were previously dissected, with any injury, trauma, and abnormality were not included in the study. All measurements were taken using a vernier caliper (Wilson Wolpert Digitronic ${ }^{\circledR}$ ) and a measurement string. Two methods were performed to compare the difference in measurements between side and sex. Each reading was recorded three times in order to obtain a weighted average.

The anatomy of the plantar arteries, their variations, origins, courses, and distributing branches were examined. The relations of the plantar arch were noted, and the entire plantar arterial arch was clearly defined. Once the entire course of the plantar arch was visible in situ, it was recorded and photographed (Samsung Galaxy Note 10.15 megapixel).
The dissection procedure was conducted as per Tank (2010) and Lisowski (2004). The data was analyzed using SPSS version 21.0 (IBM® SPSS Inc., Chicago, Illinois, USA). A $p$ value of $<0.05$ was considered to be statistically significant.

The location of the plantar arterial arch was determined by dividing the foot into three compartments: anterior; middle; and posterior. The middle was further divided into three parts: middle anterior; intermediate middle; and middle posterior (Fig. 1). The length of the plantar arterial arch was measured from the point of anastomoses between the lateral plantar artery and the deep branch of the dorsalis pedis artery (Fig. 2). Predominant blood supply to the plantar arch was determined by measuring each commissure of the entire course of the plantar arch. A larger or smaller diameter as compared to the previous measurement determined which closest contributing artery, i.e the deep branch of dorsalis pedis artery, lateral plantar artery, or both, was responsible for the dominating arterial supply.

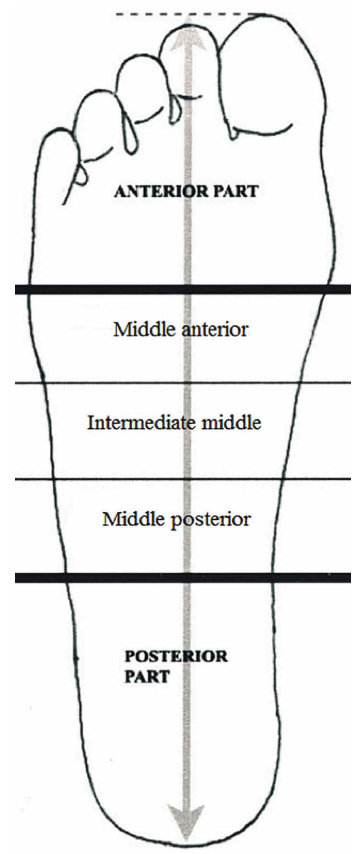

Fig.1. Schematic representation of the different quadrants the plantar side of the right foot (Adapted from Ozer et al., 2005).

\section{RESULTS}

The Plantar Arterial Arch and Variations. The plantar arterial arch was observed in all of the specimens. It was found to be fully developed in all of the specimens as well (Fig. 3) with variations in $18(45 \%)$ of the specimens.

Shape. In ten (25\%) of the specimens, a variation with the shape of the plantar arterial arch was observed. These variations were grouped as follows: i) Type A - Sharp irregular curve: observed on the left foot in one (10\%) of the 


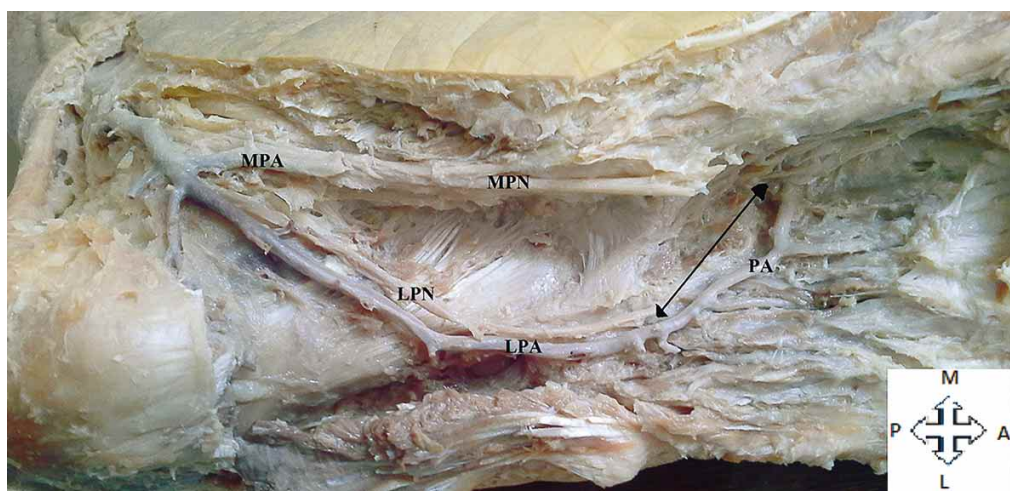

Fig. 2. Method of measurement of the plantar arterial arch. Key: PA= Plantar arch; LPA= Lateral plantar artery; LPN= Lateral plantar nerve; MPA= Medial plantar artery; MPN= Medial plantar nerve.

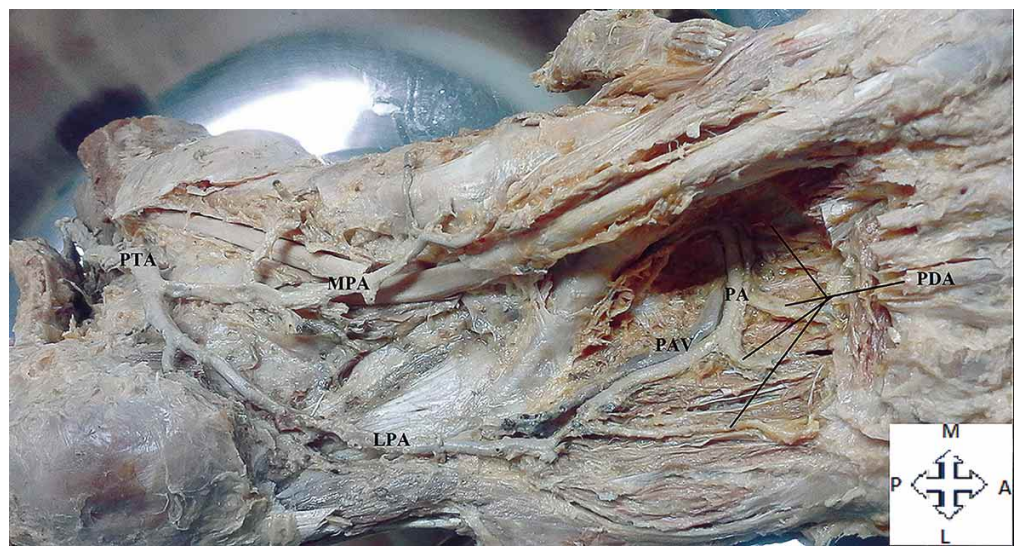

Fig. 3. Classic description of the bifurcation of the posterior tibial artery. PA= Plantar arterial arch; PAV= Plantar venous arch; MPA= Medial plantar artery; $\mathrm{PTA}=$ Posterior tibial artery; $\mathrm{PDA}=$ Plantar digital arteries; $\mathrm{LPA}=$ Lateral plantar artery.

Table I. Location of the plantar arch.

\begin{tabular}{lccc}
\hline Location & Number & $\begin{array}{c}\text { Percentage } \\
\text { incidence }\end{array}$ & Feet side \\
\hline $\begin{array}{l}\text { Anterior middle } \\
\text { Junction between anterior } \\
\text { middle and Intermediate } \\
\text { middle }\end{array}$ & $36 / 40$ & $90 \%$ & 38 right, 38 left \\
\begin{tabular}{l} 
Posterior middle \\
\hline
\end{tabular} & $0 / 40$ & $10 \%$ & 2 right, 2 left \\
\hline
\end{tabular}
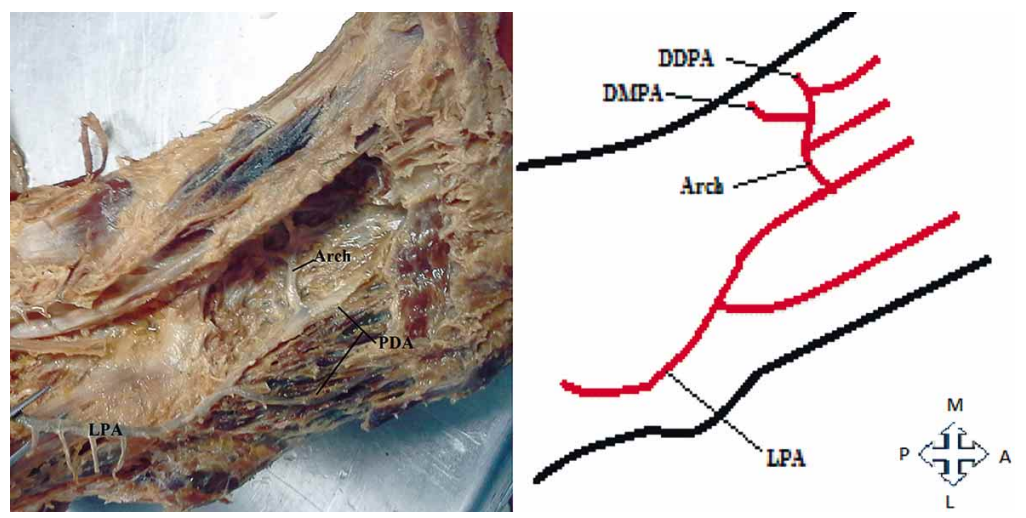

sample of variations (Fig. 4); ii) Type B Obtuse shaped curve: observed in six $(60 \%)$ of the specimens, four right feet and two left feet (Fig. 5); and iii) Type C - Spiral shaped arch: observed in three (30\%) of the specimens, two right feet and one left foot (Fig. 6). Variations with shape was more prevelant in males, six $(60 \%)$ than in females, four $(40 \%)$.

Location. The location of the plantar arterial arch within the foot was found to be in the anterior middle in 36 (90\%) [38 right; 38 left], in the junction between the anterior middle and intermediate middle in four (10\%) [2 right; 2 left], and in the posterior middle in zero $(0 \%)$ [0 right; 0 left] (Table I; Fig. 1).

Length. The length of the arch from point to point varied. There were side asymmetry in $18(45 \%)$ of the sample, in which the plantar arterial arch was found to be longer on the left, eight $(20 \%)$, and ten $(25 \%)$ was longer on the right. Symmetry occurred in $22(55 \%)$ of the sample. The mean length of the plantar arterial arch was greater in males $(4.75 \mathrm{~cm})$ than in females $(4.43 \mathrm{~cm}$ ) however there was a difference in lengths between the left $(4.44 \mathrm{~cm})$ and right $(4.41 \mathrm{~cm})$ plantar arch in females (Table II). With the use of a measurement string, similar measurement were recorded (Table II).

A comparison of the mean lengths of the plantar arterial arch with respect to side and sex was performed using a two-sample independent t-test (Table II). The measurement method using a digital caliper was found to have a p-value of 0.096 for the left plantar arch and 0.061 for the right plantar arch. This was found to be more than the standard value of 0.05 hence there were no statistical difference found between sex and side. A comparison was also performed for the methodology using a measurement string to determine, statistically, if there is a difference, a p-value was calculated to be 0.064 for the left plantar arch and 0.059 for the right plantar arch. This

Fig. 4. Irregular shape of the plantar arterial arch. Key: LPA= Lateral plantar artery; PDA= Plantar digital artery; DMPA= Deep branch of medial plantar artery; DDPA= Deep branch of dorsalis pedis artery. 
Table II. Mean measurements of the plantar arterial arch with a digital caliper and a measurement string.

\begin{tabular}{lcccccccc}
\hline \multirow{2}{*}{ Sex } & \multicolumn{9}{c}{ Measurement string } & \multicolumn{4}{c}{ Mean lengths (cm) } \\
& Right & Diameter & Left & Diameter & Right & Diameter & Left & Diameter \\
\cline { 2 - 9 } & 4.41 & 0.41 & 4.44 & 0.41 & 4.85 & 0.41 & 4.85 & 0.41 \\
Female & 4.75 & 0.43 & 4.75 & 0.43 & 5.00 & 0.43 & 4.92 & 0.43 \\
pale & 0.061 & ---- & 0.096 & --- & 0.059 & --- & 0.064 & --- \\
\hline
\end{tabular}

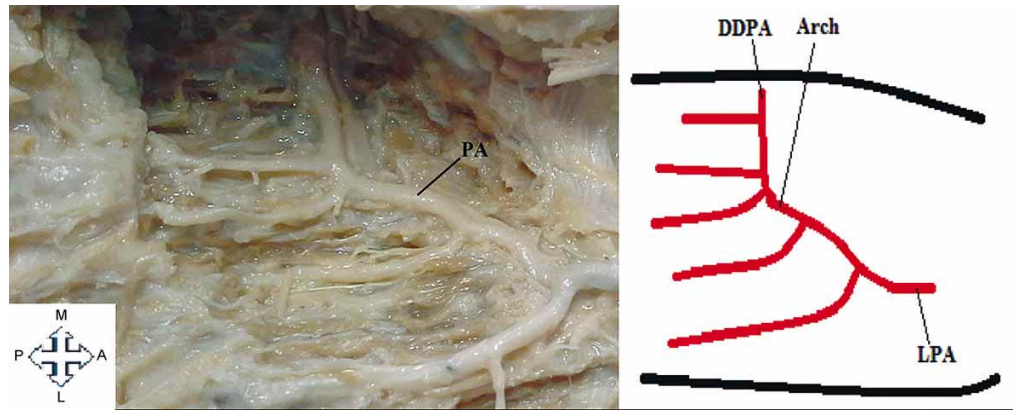

Fig. 5. The plantar arch showing an obtuse shaped curve. PA=Plantar arch; DDPA= Deep branch of dorsalis pedis artery; LPA= Lateral plantar artery.
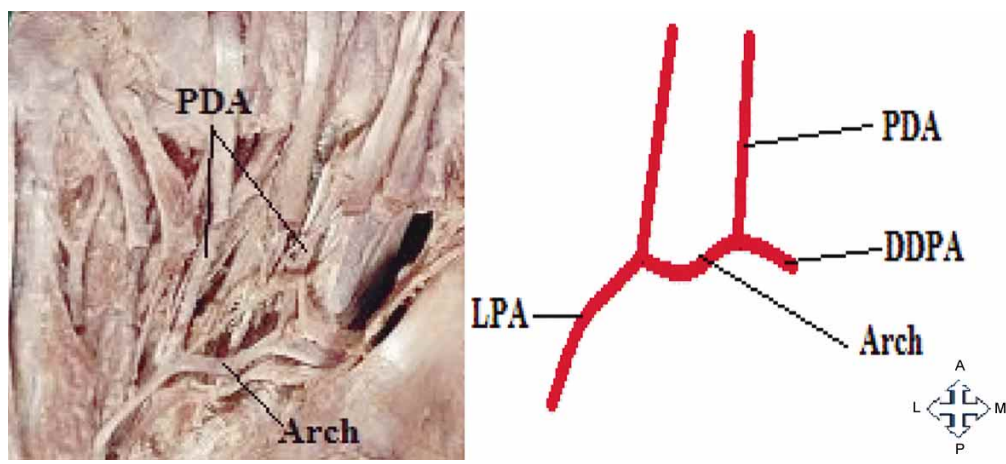

Fig. 6. Spiral shaped plantar arch. PDA= Plantar digital arteries;LPA= Lateral plantar artery.

was also more than the standard value of 0.05 hence there was no statistical difference found using this method of measurement.

Predominant Blood Flow. There were six types of predominant blood flow to the plantar arterial arch that was found: Type A - the deep branch of dorsalis pedis artery predominant in ten $(25 \%)$ of the specimens; Type $\mathrm{B}$ - the deep branch of dorsalis pedis artery supplies the second metatarsal and lateral plantar artery supplies third and fourth metatarsals in two (5\%) of the specimens; Type $\mathrm{C}$ - the deep branch of dorsalis pedis artery supplies the second to fourth metatarsal and lateral plantar artery supplies the fifth metatarsal in eight (20\%) of the specimens; Type D - the deep branch of dorsalis pedis artery supplies the second and third metatarsal and lateral plantar artery supplies the fourth and fifth metatarsal in nine $(24 \%)$ of the specimens; Type E - the deep branch of dorsalis pedis artery supplies the second metartarsal and the lateral plantar artery supplies the third to fifth metatarsals in four (10\%) of the specimens; and Type F - the lateral plantar artery is predominant in seven (21\%) of the specimens (Fig. 7).

\section{DISCUSSION}

In the present study, like many (Gabrielli et al.; Ozer et al.; Vann, 2005; Anupama, 2008) studies previously, the plantar arterial arch was found to be highly variable. Firstly, the shape of the plantar arterial arch was grouped into 3 types. Type A showed a sharp irregular curve, type B showed the arch formed an obtuse shaped curve, and type $\mathrm{C}$ showed the curve forming a spiral shape. The most common shape being type $\mathrm{B}$, found in $60 \%$ of the variant specimens. Literature reviewed did not show evidence of a study on the shape of the plantar arterial arch nor the measurement of the length of the plantar arterial arch. Therefore the findings in this study may contribute to knowledge on the variations of the plantar arterial arch.

The position of the plantar arterial arch was situated predominantely in the anterior middle region in $90 \%$ of the specimens, with the remaining situated in the junction between the anterior middle and intermediated middle region of the foot in $15 \%$; and in the intermediate middle region in 5\%. Ozer et al., stated that the location of the plantar arch was found in anterior middle of the foot in 31 $(62 \%)$, in the junction between the anterior middle and intermediate middle in 10 (20\%), and the intermediate middle in $9(18 \%)$ of the specimens. On contrary, Gabrielli et al., stated that the location of the plantar arterial arch was found in the anterior middle region in 45 $(90 \%)$, in the junction between the anterior middle and intermediate middle in $4(8 \%)$, and the intermediate middle in $1(2 \%)$ of the specimens. Hence the findings of this study are more closely related to the findings of Gabrielli et al. than that of Ozer et al. Knowledge of the positioning of the plantar 


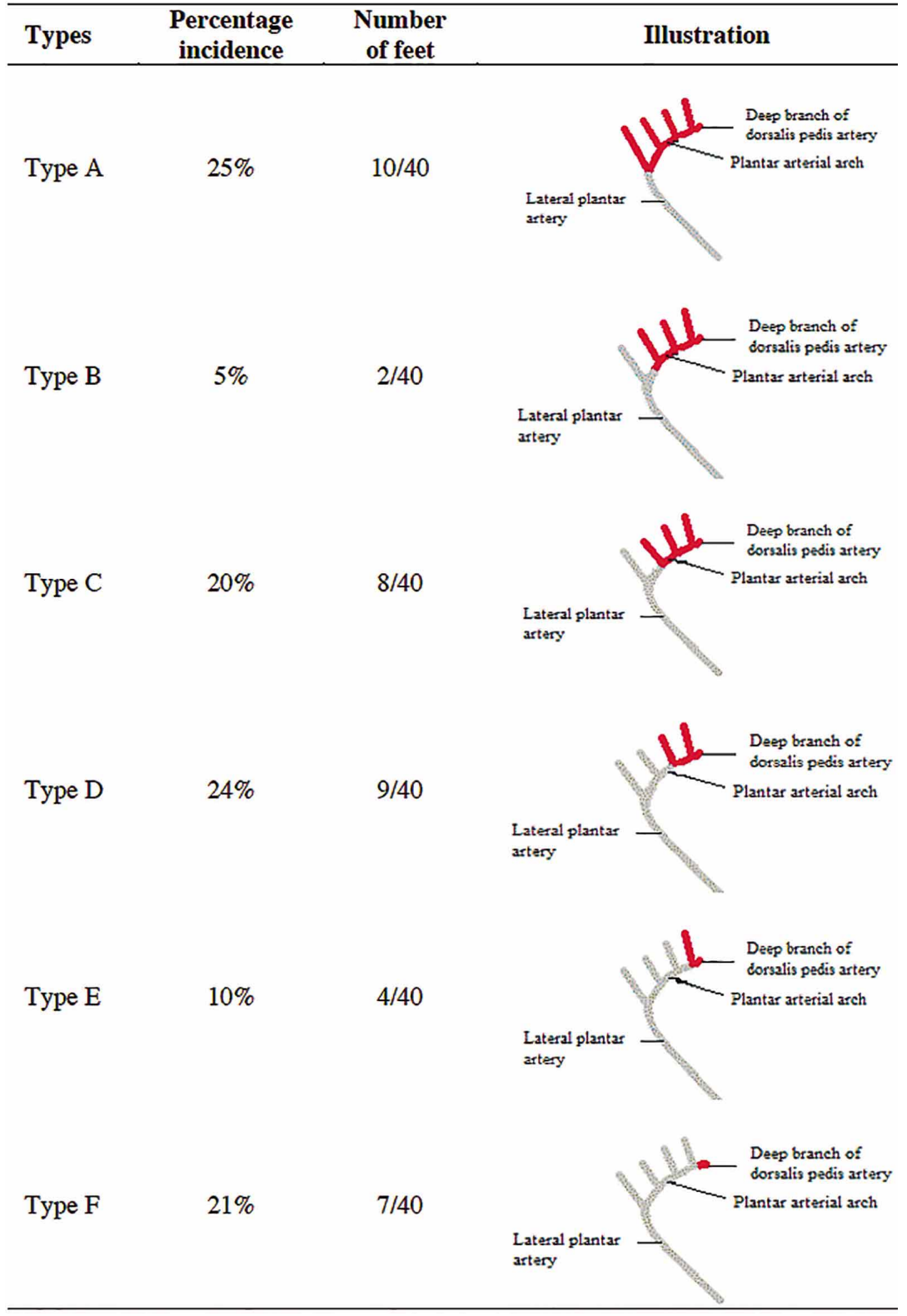

Fig. 7. Types of variations with the predominant blood flow.

arterial arch is crucial to surgeons when performing amputations of the forefoot or using the course of the artery as a landmark in surgical procedures and when dealing with the biomechanics of the foot.

The variability of the length, diameter, and in the predominant blood supply of the plantar arterial arch was first grouped into types by Hollinshead (1958), and then later by Uflacker (1997). Most studies found the standard six types of variations as described by Hollinshead. However Kelikian \& Sarrafian described seven types. The additional type described a branch of the lateral plantar artery, fibular plantar marginal artery, supplying the fifth digit. In this study, the standard six types as described by Hollinshead were observed. Hence there is no additional variation to the plantar arterial arch or its course from this study.
Vann stated that the plantar arch was supplied by the lateral plantar artery in $25 \%$, by the deep branch of dorsalis pedis artery in $40 \%$, and equal dominance in $35 \%$. Similar findings were found in this study in that the plantar arch was predominantly supplied by the lateral plantar artery in $33 \%$, by the deep branch of dorsalis pedis artery in $40 \%$ and by equal dominance in $27 \%$. Hence, in this study and that of Vann, the predominant contributor to the plantar arch is from the deep branch of dorsalis pedis artery.

The morphology and course of the plantar arch is in keeping with the standard descriptions in anatomical textbooks with the exception of variations found, such as the shape and length of the plantar arterial arch, and as stated previously, can be added to the current knowledge on the anatomy and variations of the plantar arterial arch.

\section{CONCLUSION}

Understanding of the vascular supply of the foot is of importance to general surgeons and trauma surgeons when performing plantar flaps. This study adds to existing descriptions of the plantar arterial supply of the foot, elaborating on the morphology and morphometry of the plantar arterial arch and its variations. The shape and length of the plantar arterial arch has not been documented previously and is elaborated on in this study.

The study concludes that there is asymmetry in the lengths of the plantar arterial supply of the foot. Asymmetry occurred largely in the plantar arterial arch itself as compared to its origin, the lateral plantar artery. The lengths between each branch of the plantar digital artery arising from the plantar arch were variable. Some arose closely while others arose wide apart; some even arose from the same point on the arch. This study aimed for the greater understanding on the plantar arterial arch and its variations. 
KALICHARAN, A.; PILLAY, P.; RENNIE, C. \& HAFFAJEE, M. R. Anatomía del arco plantar arterial. Int. J. Morphol., 33(1):3642, 2015.

RESUMEN: El arco plantar arterial proporciona el suministro vascular dominante de los dedos del pie, con variaciones en la longitud, forma y dominancia del suministro de sangre de parte de las arterias intervinientes. De acuerdo con la definición clásica, el arco plantar arterial se forma a partir de la arteria plantar lateral y su anastomosis con la rama profunda de la arteria dorsal del pie. En este estudio se disecaron 40 pies, de cadáveres adultos, y se observó el arco plantar con variaciones en la forma y en la distribución arterial. Se observó la descripción clásica del arco plantar en el 55\% de las muestras, con variaciones en el $45 \%$ restante. Las variaciones en cuanto a su forma se clasifican en tres tipos: Tipo A (10\%): arco plantar arterial con una forma curva, de tipo irregular agudo; Tipo B (60\%): arco de curva obtuso; tipo C (3\%): arco de curva espiral. La variación en la arteria dominante fue clasificada en seis tipos: Tipo A (25\%), la dominancia correspondiente a la rama profunda de la arteria dorsal del pie que suministra las arterias para los dedos; Tipo B (5\%), el predominio correspondiente a la arteria plantar lateral, que otorga el suministro arterial para los dedos 3 y 4; y el tipo C (20\%), la dominancia correspondiente a la rama profunda de la arteria dorsal del pie, que suministra las ramas para los dedos 2 a 4; Tipo D (24\%), igual dominio al tipo C; Tipo E (10\%), existe predominio de la arteria plantar lateral, que suministra arterias para los dedos 3 a 5; y tipo F (21\%), con predominio de la arteria plantar lateral, que otorga las arterias para los dedos. El pie se dividió en tres partes para determinar la ubicación del arco plantar arterial. La segunda parte se divide en tres porciones: media anterior (90\%), media intermedia (20\%), y media posterior (0\%). El conocimiento de la anatomía vascular del arco plantar arterial es crucial para la comprensión de los sitios de realización de amputaciones parciales.

PALABRAS CLAVE: Irrigación arterial; Variaciones; Arco plantar; Pie; Cirugía vascular.

\section{REFERENCES}

Adachi, B. Das Arteriensystem der Japaner. Kyoto, Verlag der Kaiserlich-Japanischen Universität zu Kyoto, 1928. pp. 288-91.

Anupama, K. A study of variations in plantar arterial arch with surgical perspective. Conference. Mysore, Department of Anatomy, J.S.S. Medical College, S.S. Nagar, 2008.

Bergman, R. A.; Thompson, S. A. \& Afifi, A. K. Compendium of Human Anatomic Variation. Baltimore, Urban \& Schwarzenberg, 1988. pp.88,427.

Dubreuil-Chambardel, L. Variations des artères du pelvis et du membre inférieur. Paris, Masson, 1925. pp.264-8.

Farlex. Deep plantar (arterial) arch. The Free Dictionary, Farlex, 2014. Available in: http://medicaldictionary. the freedictionary.com/deep+ plantar $+($ arterial $)+$ arch

Feneis, H. \& Dauber, W. Pocket Atlas of Human Anatomy. 4th ed. Stuttgart, Thieme, 2000.

Friedman, S. G.; Krishnasastry, K. V.; Doscher, W. \& Deckoff, S. L. Lower extremity revascularization via the lateral plantar artery. Am. Surg., 56(11):721-5, 1990.

Gabrielli, C.; Olave, E.; Mandiola, E.; Rodrigues, C. F. \& Prates, J. C. The deep plantar arch in humans: constitution and topography. Surg. Radiol. Anat., 23(4):253-8, 2001.

Hollinshead, W. H. Anatomy for Surgeons: The back and limbs. New York, A. Hoeber-Harper, 1958. V. 3. pp. 879-82.

Kelikian, A. S. \& Sarrafian, S. K. Sarrafian's Anatomy of the Foot and Ankle: Descriptive, Topographic, Functional. $3^{\text {rd }}$ ed. Philadelphia, Lippincott Williams \& Wilkins, 2011. pp.321.

Lisowski, F. P. A Guide to the Dissection of the Human Body. 2nd ed. E-Book. World Scientific Publishing, 2004. pp.121-7. Available in: http://www.worldscientific.com/ worldscibooks/10.1142/5517\#t=aboutBook

Luther, M. \& Lepäntalo, M. Arterial reconstruction to the foot arteries--a viable option? Eur. J. Surg., 163(9):659$65,1997$.

Moore, K. L.; Dalley, A. F. \& Agur, A. M. R. Clinically Orientated Anatomy. $6^{\text {th }}$ ed. Philadelphia, Wolters Kluwer Health/Lippincott Williams \& Wilkins, 2010. pp.610.

Ozer, M. A.; Govsa, F. \& Bilge, O. Anatomic study of the deep plantar arch. Clin. Anat., 18(6):434-42, 2005.

Schuenke, M.; Schulte, E. \& U. Schumacher, U. Thieme Atlas of Anatomy: General Anatomy and Musculoskeletal System. Stuttgart, Thieme, 2010. pp.503-4. 
Sidawy, A. N. Diabetic foot: Lower extremity arterial disease and limb salvage. Philadelphia, Lippincott Williams \& Wilkins, 2006. pp.77.

Standring, S. Gray's Anatomy: The Anatomical Basis of Clinical Practice. $40^{\text {th }}$ ed. New York, ChurchillLivingstone, 2009.

Tank, P. W. Grant's Dissector. $14^{\text {th }}$ ed. Philadelphia, Lippincott Williams \& Wilkins, 2010. pp.463-76.

Uflacker, R. Atlas of vascular anatomy: An angiographic approach. Philadelphia, Lippincott Williams \& Wilkins, 1997. pp.763-76.

Vann, H. M. A note on the formation of the plantar arterial arch of the human foot. Anat. Rec., 85(3):269-75, 2005.

Yamada, T.; Gloviczki, P.; Bower, T. C.; Naessens, J. M. \& Carmichael, S. W. Variations of the arterial anatomy of the foot. Am. J. Surg., 166(2):130-5, 1993.
Correspondence to:

Dr. P. Pillay

Department of Clinical Anatomy

School of Laboratory Medicine and Medical Sciences

College of Health Sciences

University of KwaZulu-Natal

Private Bag X54001

Durban

4000

SOUTH AFRICA

Email: soobramoneypa@ukzn.ac.za

Received: 19-06-2014

Accepted: 24-10-2014 